\title{
Análise espectral de solos da Região de Mogi-Guaçú (SP)
}

\author{
Spectral analysis of soils from Mogi-Guaçú (SP) Region
}

\author{
Aline Marques Genú ${ }^{1 *}$; José Alexandre Melo Demattê2; Peterson Ricardo Fiorio ${ }^{3}$
}

Resumo

Com o desenvolvimento das técnicas de sensoriamento remoto, o entendimento da resposta espectral dos solos com a finalidade de auxiliar no mapeamento e na estimativa dos seus atributos torna-se necessária. Desta forma, este trabalho teve por objetivo analisar a resposta espectral de oito perfis de solos da região de Mogi-Guaçú (SP) obtida em laboratório, e correlacioná-la com a textura e suas características químicas e mineralógicas. Os solos foram amostrados por horizontes e os dados de reflectância foram obtidos em laboratório utilizando-se um espectroradiômetro. Foi possível diferenciar a resposta espectral de cada solo e correlacioná-la com a textura, conteúdo de matéria orgânica e teor óxido de ferro. A análise da energia eletromagnética refletida permitiu avaliar a composição mineralógica dos solos com relação aos óxidos de ferro, caulinita, gibbsita e minerais 2:1. Tais resultados indicam que a análise espectral pode ser utilizada como técnica auxiliar no estudo e mapeamento dos solos.

Palavras-chave: Reflectância, atributos do solo, mineralogia, radiometria

\begin{abstract}
With the development of remote sensing techniques, the understanding of soil spectral response with the purpose to assist soil mapping and estimate soil attributes, become necessary. For this, the objective of this work was to analyze the spectral response of eight soil profiles from Mogi-Guaçú (SP) region obtained in laboratory and correlate them with soil texture and their chemical and mineralogical characteristics. The soils were sampled in each horizon and radiometric data was obtained by a spectroradiometer in laboratory. It was possible to discriminate the spectral response of each soil and relate them with texture, organic matter and iron oxides content. The analysis of reflected electromagnetic energy permitted to evaluate the soils mineralogical compounds like iron oxides, kaolinite, gibbsite and 2:1 clay minerals. These results indicate that this technique can be used as an auxiliary method in soil studies and mapping. Key words: Reflectance, soil attributes, mineralogy, radiometry
\end{abstract}

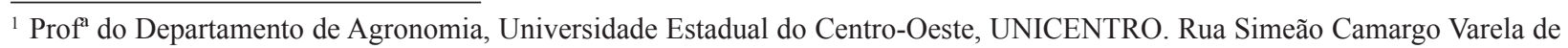
Sá, 03, CEP 85040-080, Guarapuava, PR. E-mail: agenu@unicentro.br

2 Prof. do Departamento de Ciência do Solo, ESALQ/USP. Caixa Postal 9, CEP 13418-900 Piracicaba, SP. E-mail: jamdemat@, esalq.usp.br

${ }^{3}$ Prof. do Departamento de Engenharia Rural, ESALQ/USP. Caixa Postal 9, CEP 13418-900 Piracicaba, SP. E-mail: fiorio@esalq. usp.br

* Autor para correspondência
} 


\section{Introdução}

O sensoriamento remoto tem sido considerado uma ferramenta importante em vários aspectos relacionados a agronomia principalmente no estudo do solo e da vegetação. Entretanto, com o desenvolvimento de novos sensores de aquisição de dados nos níveis orbital e aerotranspostados com resoluções cada vez melhores, informações mais detalhadas sobre o comportamento espectral dos alvos agrícolas, sob condições de campo e/ou laboratório são necessárias.

O comportamento espectral do solo é uma propriedade cumulativa derivada da resposta espectral combinada das frações mineral, orgânica e fluida que o compõe sendo que, esta resposta varia de acordo com fenômenos específicos de absorção da energia eletromagnética (faixa do visível e parte do infravermelho) pelos elementos que constituem tais frações possibilitando, desta forma, a identificação de atributos físicos, químicos e mineralógicos dos solos (MADEIRA NETTO, 1996).

Trabalhos na literatura internacional vêm sendo realizados com o intuito de determinar esta relação entre atributos do solo e a energia por ele refletida como Hunt e Salisbury (1970), Kosmas et al. (1984), Henderson et al. (1992) e Ben-Dor (2002), entretanto trabalhos relacionados ao comportamento espectral de solos brasileiros obtidos por sensores terrestres são poucos como os de Formaggio et al. (1996), Demattê (2002) e Genú e Demattê (2006) fato que têm interferência em diversos campos da ciência do solo como a pedologia.

Portanto, o presente trabalho objetiva analisar a resposta espectral de oito perfis de solos da região de Mogi-Guaçú, Estado de São Paulo, obtida em laboratório na faixa de 450 a $2500 \mathrm{~nm}$, correlacionado-a com a textura e características químicas e mineralógicas dos solos com a finalidade de auxiliar nas análises realizadas em amostras de solos para fins de levantamento e classificação.

\section{Material e Métodos}

A área localiza-se no Estado de São Paulo, na região de Mogi-Guaçú, nas coordenadas $22^{\circ} 2^{\prime} 50^{\prime \prime}$ latitude sul e $46^{\circ} 56^{\prime} 35^{\prime \prime}$ longitude oeste. O clima da região é classificado como Cwa segundo Koeppen, apresentando um período chuvoso de novembro a março e seco de julho e agosto. A litologia é representada pelo grupo Tubarão (Formações Itararé e Aquidauana). As rochas das duas formações deste grupo são extremamente variadas em textura, indo dos arenitos mais grosseiros passando por siltitos e folhelhos de natureza argilosa. Nos locais onde os vales são mais profundos ou próximos às elevações ocorrem as rochas básicas da Formação Serra Geral.

Oito perfis de solo foram descritos (LEMOS et al., 2005) e amostras dos horizontes foram coletadas e analisadas quimicamente para $\mathrm{pH}$ $\left(\mathrm{CaCl}_{2}\right)$, teor de matéria orgânica, fósforo, potássio, magnésio, cálcio, alumínio e hidrogênio mais alumínio, segundo metodologias descritas em Raij et al. (1987) e determinados os teores de areia, silte e argila de acordo com Camargo et al. (1986).

Com o resultado das análises e a descrição dos solos, os perfis foram classificados de acordo com EMBRAPA (2006) como sendo: Perfil 1 - Argissolo Vermelho-Amarelo distrófico típico (PVAd), Perfil 2 - Argissolo Vermelho-Amarelo distrófico arênico (PVAd1), Perfil 3 - Argissolo VermelhoAmarelo distrófico latossólico (PVAd2), Perfil 4 Cambissolo Háplico Tb distrófico típico (CXbd), Perfil 5 - Gleissolo Melânico Tb distrófico típico (GMd), Perfil 6 - Latossolo Vermelho-Amarelo distrófico típico (LVAd), Perfil 7 - Latossolo Vermelho distroférrico típico (LVdf), Perfil 8 Neossolo Quartzarênico órtico típico (RQo).

As amostras de terra encaminhadas para laboratório foram moídas, peneiradas (malha de $2 \mathrm{~mm}$ ) e secas em estufa por $24 \mathrm{~h}$ à $45^{\circ} \mathrm{C}$ para a leitura de sua reflectância, que foi obtida utilizandose o espectroradiômetro Infra Red Intelligent Spectroradiometer (IRIS), com resolução de 2 $\mathrm{nm}$ entre 450 e $1100 \mathrm{~nm}$ e $4 \mathrm{~nm}$ entre 1100 e $2500 \mathrm{~nm}$. A geometria do sistema baseou-se no posicionamento perpendicular do sensor em relação à amostra, que foi colocada em placa de petri, 
mantendo entre ambos uma distância de $27 \mathrm{~cm}$. A fonte de iluminação, uma lâmpada halógena de 650 W com refletor parabólico e feixe não-colimado para o plano do alvo, foi posicionado a $61 \mathrm{~cm}$ do alvo (amostra), formando um ângulo de $20^{\circ}$ com o zênite (DEMATTÊ; GARCIA, 1999). A reflectância bidirecional aqui utilizada foi definida de acordo com Nicodemus et al. (1977).

Os dados foram posteriormente calibrados e filtrados por software específico denominado Conviris (STEFFEN, 1997), para diminuição dos ruídos e facilitar a interpretação das curvas espectrais.

Para melhor observação das feições de absorção nas curvas espectrais, foi obtida a segunda derivada nas amostras do horizonte B, a partir da metodologia desenvolvida por Savitzky e Golay (1964).

\section{Resultados e Discussão}

\section{Comportamento espectral dos solos}

A análise das curvas espectrais dos perfis de solos estudados mostrou a existência de características distintas quanto à intensidade e presença das bandas de absorção (Figuras 1 e 2). O Neossolo Quartzarênico (RQo) (Figura 1a) é um solo de textura arenosa, baixo teor de matéria orgânica (Tabela 1) causando uma resposta espectral alta devido à mineralogia deste solo ser constituída principalmente de quartzo (FORMAGGIO et al., 1996); embora ocorram também caulinita e gibbsita.

As diferenças encontradas nas respostas espectrais dos dois Latossolos (LVAd e LVdf) estão relacionadas principalmente ao material de origem e ao teor de argila (Tabela 1). O LVdf é formado sobre rochas básicas da formação Serra Geral o que confere a ele alto teor de argila e baixa reflectância ao contrário do LVAd cuja textura é média (Tabela 1). Outro fator importante relacionado a baixa intensidade de reflectância do LVdf, está na presença de minerais opacos como a magnetita que absorve energia em todo o espectro eletromagnético conforme verificado por Hunt, Salisbury e Lenhoff (1971) e ratificado por Demattê et al. (2001) estudando 8 classes de solos do município de Mogi-Mirim. Por outro lado, ambos os solos apresentaram bandas de absorção pouco intensas em $1400 \mathrm{~nm}, 1900 \mathrm{~nm}$ (Figura 2c) e mais altas em $2200 \mathrm{~nm}$ demonstrando a mineralogia caulinítica (Figura 2d) destes solos, concordando com os resultados obtidos por Fiorio (2002) e Demattê (2002). Além disso, como estes solos são bastante homogêneos em todo o perfil, a forma da curva para os três horizontes é similar (Figura 1b e 1c), havendo apenas um aumento da reflectância com o aumento da profundidade devido à diminuição do teor de matéria orgânica neste sentido, o que também foi observado por Galvão, Vitorello e Formaggio (1997).

O Gleissolo (GMd) apresenta baixa intensidade de reflectância para os horizontes A e Btg (Figura $_{1}$ 1d), devido aos elevados teores de matéria orgânica (Tabela 1), que absorvem energia reduzindo o albedo do solo (HENDERSON et al., 1992) enquanto o horizonte $\mathrm{Btg}_{2}$, com menor teor de matéria orgânica, apresenta alta reflectância. Este solo não apresenta bandas de absorção para os óxidos de ferro, na faixa de $450 \mathrm{~nm}$ a $550 \mathrm{~nm}$ (Figura 2b) mas verifica-se a presença da banda de absorção da caulinita (2200 nm) (Figura 2d) concordando com Demattê (2002).

Os Argissolos, assim como os Latossolos também apresentaram respostas distintas apesar de diferirem apenas no quarto nível categórico (subgrupos). O Argissolo Vermelho-Amarelo distrófico típico (PVAd) (Figura 1e) possui uma alta reflectância devido a sua textura e o baixo teor de matéria orgânica (Tabela 1).

A resposta espectral do PVAd mostra também intensas feições de absorção da água (1400 e 1900 $\mathrm{nm}$ ) e também em $2200 \mathrm{~nm}$ indicando a presença de mineralogia 2:1 neste solo (Figura 2c). Resultado similar foi obtido por Demattê et al. (2001) que verificaram, para dois Argissolos VermelhoAmarelos distróficos da região de Mogi-Mirim, que

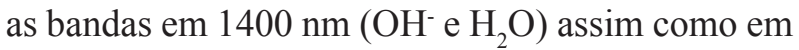
$1900 \mathrm{~nm}\left(\mathrm{H}_{2} \mathrm{O}\right)$ foram mais pronunciadas, indicando a presença de mineralogia 2:1, o que foi confirmado por difratometria de raio-X. 


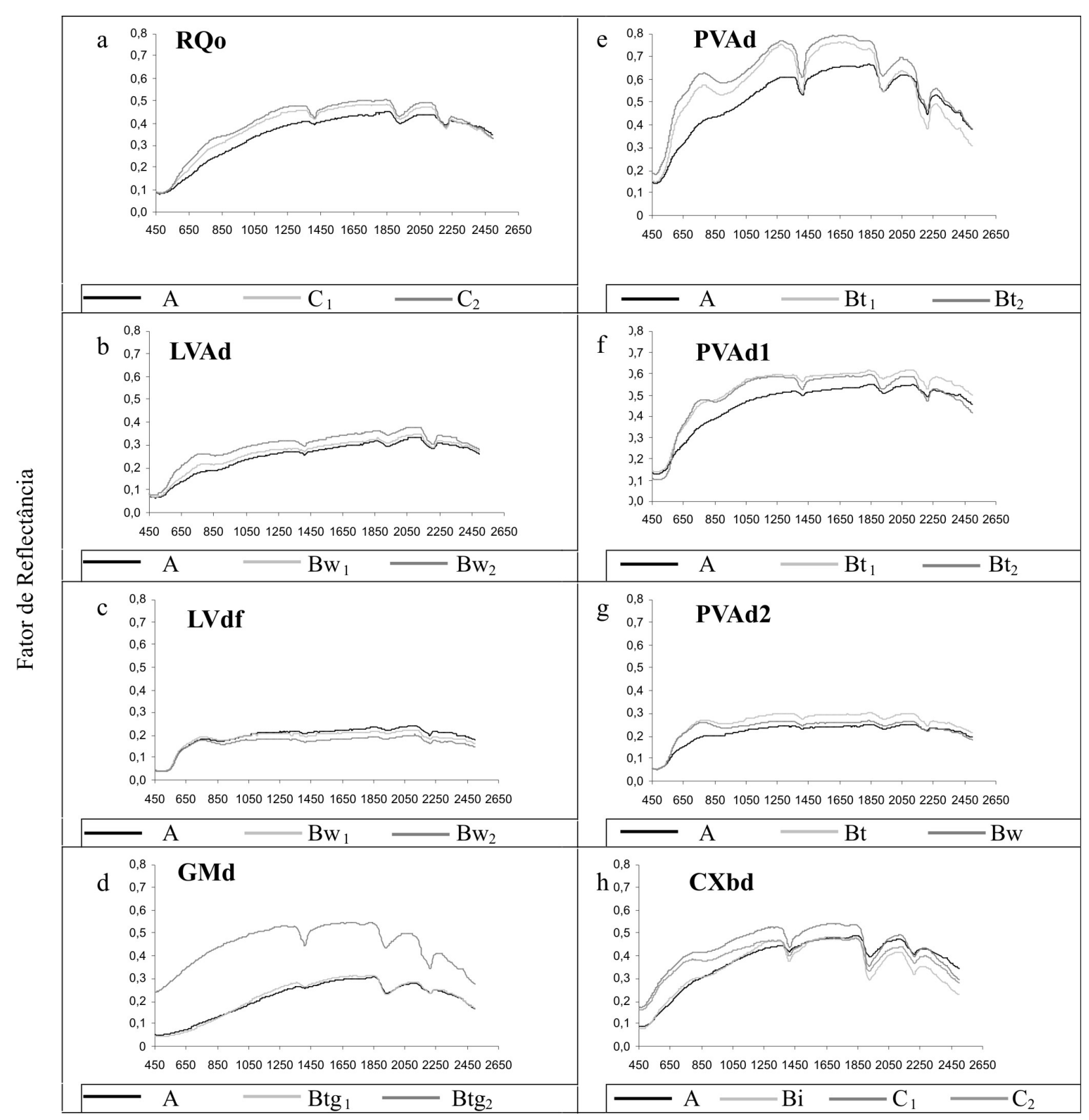

Comprimento de onda $(\mathrm{nm})$

Figura 1. Curvas espectrais dos solos da área de estudo: a. Neossolo Quartzarênico órtico típico, b. Latossolo Vermelho-Amarelo distrófico típico, c. Latossolo Vermelho distroférrico típico, d. Gleissolo Melânico Tb distrófico típico, e. Argissolo Vermelho-Amarelo distrófico típico, f. Argissolo Vermelho-Amarelo distrófico arênico, g. Argissolo Vermelho-Amarelo distrófico latossólico, h. Cambissolo Háplico Tb distrófico típico. 


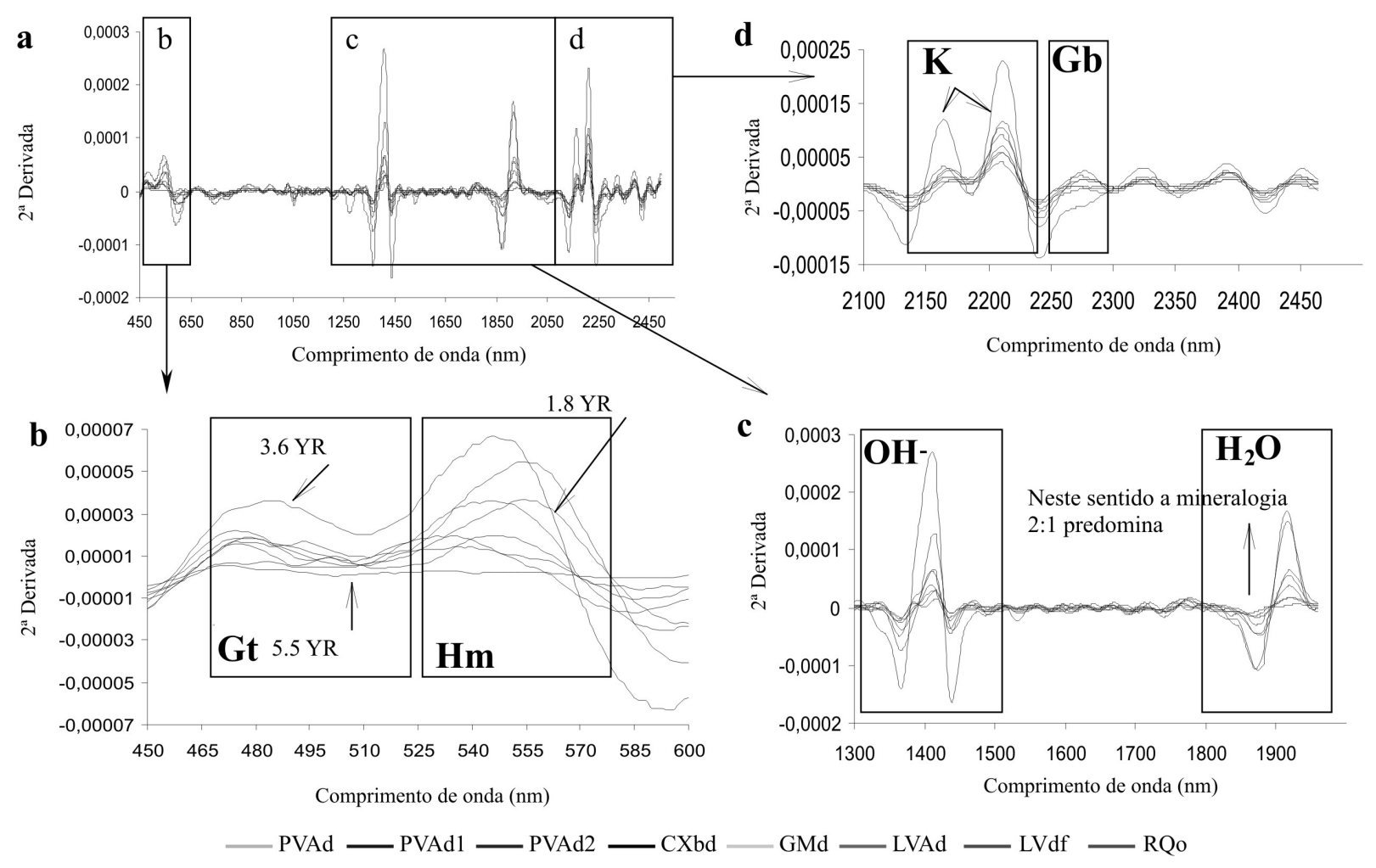

Figura 2. Segunda derivada do horizonte $B$ dos perfis estudados (a) e os detalhamentos para análise da Goethita (Gt) e Hematita (Hm) (b), bandas de absorção da água (OH- e $\left.\mathrm{H}_{2} \mathrm{O}\right)$ (c) e da Caulinita (K) e Gibbsita (Gb) (d).

O Argissolo Vermelho-Amarelo distrófico arênico (PVAd1) (Figura 1f), não apresenta, na faixa entre 450 e $900 \mathrm{~nm}$ para o horizonte $\mathrm{A}$, a feição de absorção relativa a presença dos óxidos de ferro, além de ter uma reflectância mais baixa que os horizontes $\mathrm{Bt}_{1}$ e $\mathrm{Bt}_{2}$, fato este relacionado à presença da matéria orgânica (Tabela 1) que mascara o efeito do ferro na resposta espectral do solo assim como absorve energia diminuindo a sua intensidade (FERNANDES et al., 2004). A mineralogia é predominantemente caulinítica, como pode ser observado pela banda de absorção em 2200 nm (Figura 2d).

O Argissolo Vermelho-Amarelo distrófico latossólico (PVAd2) (Figura 1g) por sua vez apresenta a forma da curva semelhante a do LVdf com a região entre $450 \mathrm{~nm}$ e $550 \mathrm{~nm}$ apresentando a banda de absorção devido a presença dos óxidos de ferro (Figura 2b) o que também foi observado por Demattê e Garcia (1999).

O Cambissolo (CXbd) por ser um solo menos intemperizado, o que pode ser verificado pela sua alta CTC (Tabela 1), apresenta intensas bandas de absorção da água assim como em 2200 nm, indicando mineralogia 2:1 (Figura 2c). Demattê, Campos e Alves (2000) verificaram que solos Litólicos (Neossolo Litólico) apresentaram vermiculita e mica em sua composição, detectados pelos difratogramas de raio-X e, assim como o CXbd, também mostraram bandas de absorção intensas em $1400 \mathrm{~nm}, 1900 \mathrm{~nm}$ e $2200 \mathrm{~nm}$. 


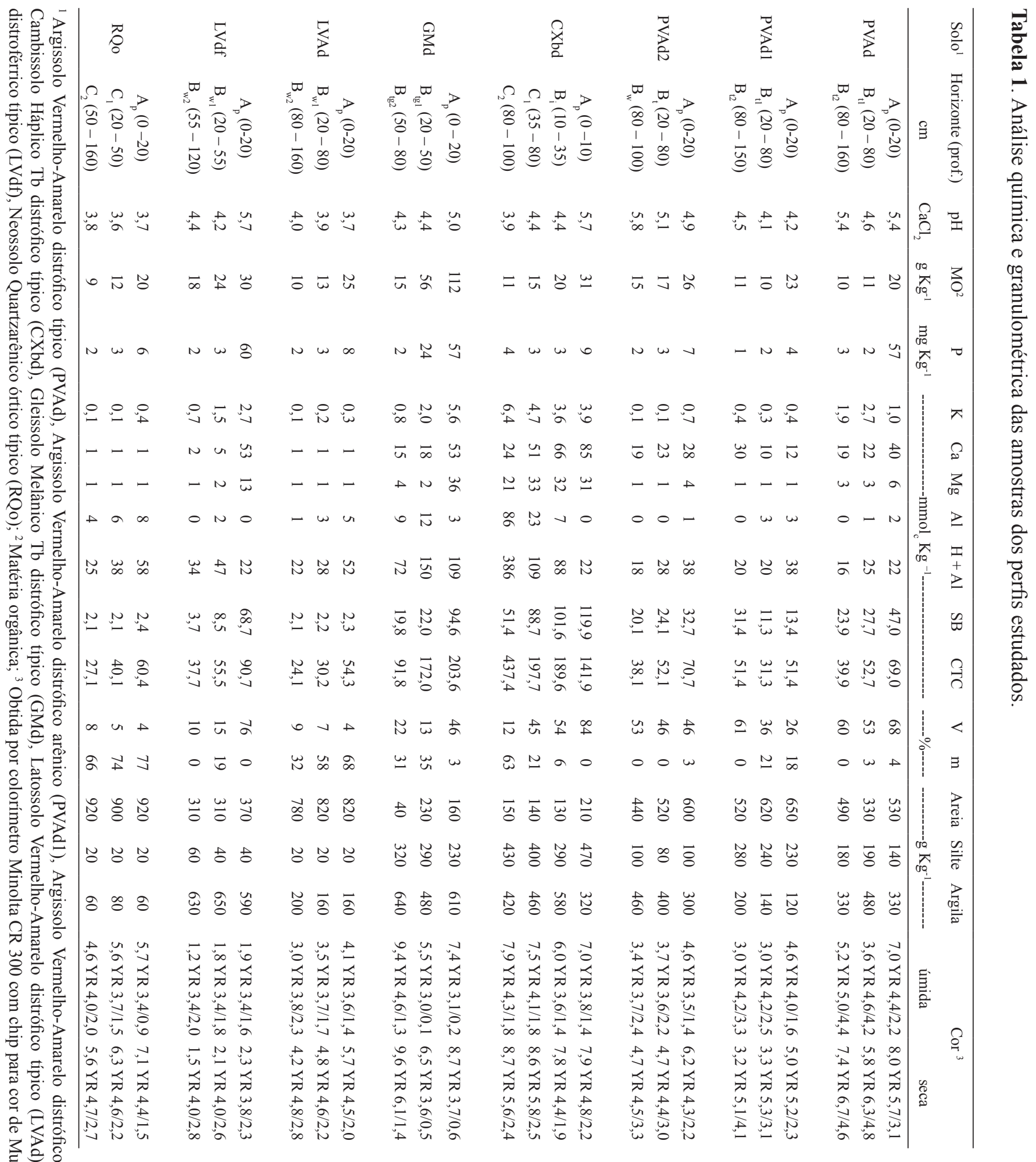


Feições de absorção das curvas espectrais

Óxidos de ferro

Goethita $(\mathrm{FeOOH})$ e hematita $\left(\mathrm{Fe}_{2} \mathrm{O}_{3}\right)$ são as formas mais freqüentes de ferro $\left(\mathrm{Fe}^{3+}\right)$ encontradas nos solos, resultantes da oxidação do ferro $\left(\mathrm{Fe}^{2+}\right)$ presente nos minerais primários durante o processo de formação do solo (CORNELL; SCHWERTMANN, 1996).

A feição espectral do ferro, na faixa do visível ao infravermelho, resulta das transições eletrônicas do $\mathrm{Fe}^{3+}$ porém, os diferentes óxidos de ferro possuem respostas espectrais em comprimentos de onda distintos devido às diferenças estruturais dos minerais (SHERMAN; WAITE, 1985). A hematita e a goethita apresentam o $\mathrm{Fe}^{3+}$ em coordenação octaedral com o oxigênio, entretanto, a goethita possui as ligações do $\mathrm{OH}^{-}$em posições diferentes do $\mathrm{O}^{2-}$ na hematita (BENDOR, 2002).

Os óxidos de ferro apresentam sua principal banda de absorção, que ocorre devido a transferência de carga metal-ligante $\left(\mathrm{Fe}^{3+}-\mathrm{O}^{2-}\right)$, na faixa do ultravioleta, entretanto, Hunt, Salisbury e Lenhoff (1971) observaram que outra banda de menor intensidade para os óxidos de ferro ocorre na faixa de 450-600 nm (visível).

Os solos estudados apresentaram feição de absorção no comprimento de onda verificado para os óxidos de ferro, porém como esta é uma banda de baixa absorção e os diferentes óxidos apresentam respostas distintas, a determinação de qual tipo está presente no solo torna-se difícil desta forma, para detecção da presença destes elementos realizou-se a derivada segunda do horizonte B dos solos estudados.

Observando-se as curvas da derivada segunda dos solos para óxidos de ferro (Figura 2b) verificase que as feições de absorção da goethita e hematita são distintas e ocorrem na faixa de $476 \mathrm{~nm}$ a 493 $\mathrm{nm}$ para goethita e $521 \mathrm{~nm}$ a $565 \mathrm{~nm}$ para hematita, similar ao obtido por Scheinost et al. (1998) e por Sherman e Waite (1985) que verificaram bandas em $530 \mathrm{~nm}$ e $480 \mathrm{~nm}$ para hematita e goethita, respectivamente. Morris et al. (1985), no entanto, verificaram outras bandas de absorção para estes óxidos em faixas como 845 a $870 \mathrm{~nm}$ para hematita e, 900 a $930 \mathrm{~nm}$ e $650 \mathrm{~nm}$ para goethita.

Os óxidos, mesmo em baixas concentrações, têm um alto poder de pigmentação indo, desde solos vermelhos (hematíticos) com matiz 7,5 $\mathrm{R}$ (segundo a notação Munsell) até 2,5 Y onde a goethita é o óxido de ferro exclusivo e, os matizes intermediários de cor são o resultado da mistura destes minerais (BARRÓN; DE MELLO; TORRENT, 2000, FERNANDES et al., 2004).

A relação da cor do solo com a presença de óxidos de ferro pode ser observada nos solos estudados (Figura 2b e Tabela 1). Os solos vermelho-amarelos (LVAd, PVAd, PVAd1 e PVAd2) apresentam as bandas de absorção tanto da hematita quanto da goethita porém, com diferenças quanto a intensidade da resposta espectral devido a textura e teor de matéria orgânica apresentada por cada um deles enquanto o LVdf possui apenas a feição da hematita por ser um solo de matiz vermelha.

O GMd não apresenta nenhuma feição para os óxidos devido ao alto teor de matéria orgânica que mascara os óxidos ou a inexistência destas formas de ferro em sua mineralogia (Figura 2b).

Scheinost e Schwertmann (1999) determinaram que a matiz de solos hematíticos é próxima da matiz do mineral puro sendo o mesmo verdadeiro para a goethita. Tal fato confirma a relação entre a cor e a presença dos óxidos de ferro no solo e ratifica os resultados aqui verificados.

\section{Minerais 2:1, caulinita e gibbsita}

Os solos avaliados apresentaram bandas de absorção em três comprimentos de onda específicos na faixa do infravermelho: 1400, 1900 e 2200 nm. Basicamente, estas feições espectrais estão associados a "overtones" (transição de um modo vibracional de um estado de energia para outro nível de energia acima ou abaixo do original) e 
combinações (freqüências associadas a mais de um modo vibracional) de vibrações fundamentais do grupo $\mathrm{OH}^{-}$e da água (BEN-DOR; IRONS; EPEMA, 1999; CHABRILLAT et al., 2002).

A hidroxila está presente na estrutura dos minerais e possui apenas uma vibração ativa no infravermelho, situada em torno de $2750 \mathrm{~nm}$, porém, com um "overtone" próximo a $1400 \mathrm{~nm}$ (CLARK et al., 1990), além disso, a combinação deste grupo com outros elementos como, por exemplo, o $\mathrm{Al} \mathrm{e}$ o $\mathrm{Mg}$, produzem feições de absorção próximas de $2200 \mathrm{~nm}$ e $2300 \mathrm{~nm}$ e são diagnósticas dos minerais de argila (CHABRILLAT et al., 2002).

Os minerais 2:1, além das bandas em 1400 e $2200 \mathrm{~nm}$ também apresentam uma feição intensa em $1900 \mathrm{~nm}$ pela presença da água entre as lâminas do mineral (FROST et al., 2001). Tal fato demonstra que os solos PVAd e CXbd aqui apresentados possuem mineralogia 2:1 (Figura 2c). Por outro lado, os mesmos solos também apresentam uma feição dupla em $2200 \mathrm{~nm}$ causada pela ligação Al$\mathrm{OH}$, caracterizando a existência da caulinita (Figura 2d). Este resultado está de acordo com o obtido por Demattê et al. (2001) que verificaram a presença de minerais 2:1 e caulinita simultaneamente em Argissolos e Cambissolos de Mogi-Mirim nas curvas espectrais assim como na difratometria de raio-X.

Da mesma forma, verificou-se para os demais perfis de solos a presença de caulinita, devido às feições em 1400 e $2200 \mathrm{~nm}$ (Figura 2d). Entretanto, uma banda de pequena intensidade em $1900 \mathrm{~nm}$ também foi observada para estes solos, mas de acordo com Clark et al. (1990), isto está relacionado com a presença de água na amostra e não com a existência de minerais $2: 1$.

Outro mineral muito encontrado nos solos tropicais é a gibsita e, segundo verificado por Madeira Netto (1996), apresenta feição espectral em $2265 \mathrm{~nm}$ devido a vibração do $\mathrm{OH}^{-}$combinado com o alumínio. Nos solos estudados, com exceção do PVAd (Figura 3c), todos apresentaram este mineral.
Resultado semelhante foi obtido por Demattê et al. (2000), no qual um Podzólico Vermelho Escuro de Piracicaba, não apresentou gibsita na sua mineralogia.

\section{Conclusões}

1 - Granulometria, matéria orgânica e composição mineralógica são os principais fatores que influenciam as feições de absorção e intensidade de reflectância.

2 - A radiometria dos solos permitiu identificar a composição mineralógica dos solos com relação à presença de óxidos de ferro, minerais 2:1, caulinita e gibbsita.

3 - Os óxidos de ferro, hematita e goethita, apresentam respostas espectrais em comprimentos de onda distintos devido às suas características estruturais específicas, e estão intimamente ligados a cor do solo.

\section{Referências}

BARRÓN, V.; DE MELLO, J. W. V.; TORRENT, J. Caracterização de óxidos de ferro em solos por espectroscopia de reflectância difusa. In: NOVAIS, R. F.; ALVAREZ, V. V. H.; SCHAEFER, C. E. G. R. (Ed.). Tópicos em ciência do solo. Viçosa: Sociedade Brasileira de Ciência do Solo, 2000. v. 1, p. 139-162.

BEN-DOR, E. Quantitative remote sensing of soil properties. Advances in Agronomy, USA, v. 75, p. 173243, 2002.

BEN-DOR, E.; IRONS, J. R.; EPEMA, G. F. Soil reflectance. In: RENCZ, A. N. (Ed.). Remote sensing for earth sciences: manual of remote sensing. 3 ed. Danver: John Wiley, 1999. v. 3, p. 111-188.

CAMARGO, A. O.; MONIZ, A. C.; JORGE, J. A.; VALADARES, J. M. Métodos de análise química, mineralógica e física de solos do IAC. Campinas: Instituto Agronômico, 1986. 94 p. (IAC. Boletim técnico, 106).

CHABRILLAT, S.; GOETZ, A. F. H.; KROSLEY, L.; OLSEN, H. W. Use of hyperspectral images in the identification and mapping of expansive clays soils and the role of spatial resolution. Remote Sensing of Environment, New York, v. 82, n. 2/3, p. 431-445, 2002. 
CLARK, R. N.; KING, T. V. V.; KLEIWA, M.; SWAYZE, G. A.; VERGO, N. High spectral resolution reflectance spectroscopy of minerals. Journal of Geophysical Research, Washington, v. 95, n. B8, p. 12653-12680, 1990.

CORNELL, R. M.; SCHWERTMANN, U. The iron oxides. Structure, properties, reactions, occurrence and uses. Weinheim: VCH, 1996. 573 p.

DEMATTÊ, J. A. M.; GARCIA, G. J. Alteration of soil properties through a weathering sequence as evaluated by spectral reflectance. Soil Science Society of America Journal, Madison, v. 63, n. 2, p. 327-342, 1999.

DEMATTÊ, J. A. M. Characterization and discrimination of soils by their electromagnetic energy. Pesquisa Agropecuária Brasileira, Brasília, v. 37, n. 10, p.14451458, 2002.

DEMATTÊ, J. A. M.; CAMPOS, R. C.; ALVES, M. C. Avaliação espectral de solos desenvolvidos em uma topossequência de diabásio e folhelho da região de Piracicaba, SP. Pesquisa Agropecuária Brasileira, Brasília, v. 35, n. 12, p.2447-2460, 2000.

DEMATTÊ, J. A. M.; DEMATTÊ, J. L. I.; CAMARGO, W. P.; FIORIO, P. R.; NANNI, M. R. Remote sensing in the recognition and mapping of tropical soils developed on topographic sequences. Mapping Science and Remote Sensing, Birmingham, v. 38, n. 2, p. 79-102, 2001.

EMPRESA BRASILEIRA DE PERQUISA AGROPECUÁRIA - EMBRAPA. Centro Nacional de Pesquisa de Solos. Sistema brasileiro de classificação de solos. 2. ed. Rio de Janeiro: Embrapa Solos. 2006. 306 p.

FERNANDES, R. B. A.; BARRÓN, V.; TORRENT, J.; FONTES, M. P. F. Quantificação de óxidos de ferro de latossolos brasileiros por espectroscopia de reflectância difusa. Revista Brasileira de Ciência do Solo, Viçosa, MG, v. 28, n. 2, p. 245-257, 2004.

FIORIO, P. R. Dados radiométricos obtidos nos níveis terrestre e orbital na avaliação de solos. 2002. Tese. (Doutorado em Solos e Nutrição de Plantas) - Escola Superior de Agricultura Luiz de Queiroz, Piracicaba.

FORMAGGIO, A. R.; EPIPHANIO, J. C. N.; VALERIANO, M. M.; OLIVEIRA, J. B. Comportamento spectral (450-2450 nm) de solos tropicais de São Paulo. Revista Brasileira de Ciência do Solo, Viçosa, MG, v. 20, n. 3, p. 467-474, 1996.

FROST, R. L.; LOCOS, O. B.; RUAN, H.; KLOPROGGE, J. T. Near-infrared and mid-infrared spectroscopic study of sepiolites and palygorskites. Vibrational Spectroscopy, Maryland Heights, v. 27, n. 1, p. 1-13, 2001.
GALVÃO, L. S.; VITORELlO, I.; FORMAGGIO, A. R. Relationships of spectral reflectance and color among surface and subsurface horizons of tropical soil profiles. Remote Sensing of Environment, New York, v. 61, n. 1, p. 24-33, 1997.

GENÚ, A. M.; DEMATTÊ, J. A. M. Determination of soil attribute contents by means of reflected electromagnetic energy. International Journal of Remote Sensing, London, v. 27, n. 21, p. 4807-4818, 2006.

HENDERSON, T. L.; BAUMGARDNER, M. F.; FRANZMEIER, D. E.; STOTT, D. E.; COSTER, D. C. High dimensional reflectance analysis of soil organic matter. Soil Science Society of America Journal, Beltsville, v. 56, n. 3, p. $865-872,1992$.

HUNT, G. R.; SALISBURY, G. W. Visible and near infrared spectra of minerals and rocks I - Silicate minerals. Modern Geology, London, v. 2, p. 283-300, 1970.

HUNT, G. R.; SALISBURY, G. W.; LENHOFF, C. J. Visible and near infrared spectra of minerals and rocks III - Oxides and hydroxides. Modern Geology, London, v. 2, p. 195-205, 1971.

KOSMAS, C. S.; CURI, N.; BRYANT, R. B.; FRANZMEIER, D. P. Characterization of iron oxides minerals by second-derivative visible spectroscopy. Soil Science Society of America Journal, Madison, v. 48, n. 2, p. 401-405, 1984.

LEMOS, R. C.; SANTOS, R. D.; SANTOS, H. G.; KER, J. C.; ANJOS, L. H. C. Manual de descrição e coleta de solos no campo. 5. ed. Viçosa, MG: SBCS, 2005. 92 p.

MADEIRA NETTO, J. S. Spectral reflectance properties of soils. Photo Interprétation, Paris, v. 34, n. 2, p. 59-70, 1996.

MORRIS, R. V.; LAUER JUNIOR, H. V.; LAWSON, C. A.; GIBSON JUNIOR, E. K.; NACE, G. A.; STEWART, C. Spectral and other physicochemical properties of submicron powders of hematite $\left(\mathrm{Fe}_{2} \mathrm{O}_{3}\right)$, maghemite $\left(\mathrm{Fe}_{2} \mathrm{O}_{3}\right)$, magnetite $\left(\mathrm{Fe}_{3} \mathrm{O}_{4}\right)$, goethite $(\mathrm{FeOOH})$ and lepidocrocite $(\mathrm{FeOOH})$. Journal of Geophysical Research, Washington, v. 90, n. B4, p. 3126-3144, 1985.

NICODEMUS, F. E.; RICHMOND, J. C.; HSIA, J. J.; GINSBERG, I. W.; LIMPERIS, T. Geometrical considerations and nomenclature for reflectance. Washington, U.S.: Departmente of Commerce, 1977. 52 p. (NBS Monograph, 160).

RAIJ, B. van.; QUAGGIO, J. A.; CANTARELLA, H.; FERREIRA, M. E.; LOPES, A. S.; BATAGLIA, C. O. Análise química do solo para fins de fertilidade. Campinas: Fundação Cargill,1987. 170 p. 
SAVITZKY, A.; GOLAY, M. J. E. Smoothing and differentiation of data by simplified least square procedures. Analytical Chemistry, Washington, v. 36, n. 8, p. 16271639, 1964.

SCHEINOST, A. C.; SCHWERTMANN, U. Color identification of iron oxides and hydroxysulfates: use and limitations. Soil Science Society of America Journal, Madison, v. 63, n. 5, p. 1463-1471, 1999.

SCHEINOST, A. C.; CHAVERNAS, A.; BARRÓN, V.; TORRENTE, J. Use and limitations of second-derivative diffuse reflectance spectroscopy in the visible to near- infrared range to identify and quantify Fe oxides minerals in soils. Clays and Clays Minerals, Chantilly, v. 46, n. 5, p.528-536, 1998.

SHERMAN, D. M.; WAITE, T. D. Electronic spectra of $\mathrm{Fe}^{3+}$ oxides hydroxides in the near IR to near UV. American Mineralogist, Chantilly, v. 70, n. 11/12, p. 12621269, 1985.

STEFFEN, C. Conviris: software para tratamento de dados espectrais obtidos em laboratório. São José dos Campos: Instituto Nacional de Pesquisas Espaciais, 1997. 